\title{
Relationship of Ground Hail Damage Patterns to Features of the Synoptic Map in the Upper Great Plains of the United States
}

\author{
E. M. FRISBY \\ Raven Industries, Sioux Falls, S. D. \\ (Manuscript received 17 July 1961, in revised form 23 October 1961) \\ ABSTRACT

\begin{abstract}
Hail damage at the ground, plotted from insurance records for ten years of crop season hail storms, is found to fall into recognizable pattern groups, associated with specific features of the synoptic map. Speed of movement of the synoptic systems appears to exert considerable influence on the extent and degree of ground hail damage.
\end{abstract}

\section{Introduction}

In the absence of a dense hail reporting network for the northern Great Plains of the United States, hail insurance claims have been plotted on township maps of South Dakota for the 10-yr period 1951 to 1960 , for each hail storm affecting the crop during each crop season. Since the east side of the State was most consistently insured throughout this period, and was planted almost entirely to corn, it was decided to focus attention on hail damage patterns originating east of the Missouri. Insurees in this area provided a close equivalent to an observing network with one observer to every square mile of territory.

Patterns of hail damage for individual storms were rarely complete within the roughly 200 by $400 \mathrm{sq} \mathrm{mi}$ comprised in South Dakota territory east of the River. Accordingly, hail claim data were obtained for 1959 and 1960 for Minnesota, Iowa and Nebraska, and hailstorm ground damage patterns developed for each storm affecting eastern South Dakota and continuing into the other three states. From these data, hail storms may be timed by date, but not by hour. No information is available on hail size.

U. S. Weather Bureau surface weather maps for the main synoptic hours were used throughout the analysis.

\section{Analysis of the data}

According to the insurance record, damaging hail storms occurred somewhere in South Dakota, on some 515 days during the crop seasons 1951 to 1960 , giving a 10-yr average of about 52 per year between May and September. From the plots of damage claims, ground hail damage patterns were found to fall into four main groups:

Group 1. Those occurring in swath-type patterns with a northwest to southeast slant. These often ap- peared in formation as a series of parallel straight lines, Fig. 1a.

Group 2. Those occurring in groups along a slightly curved line or series of lines lying southwest to northeast, Fig. $1 \mathrm{~b}$.

Group 3. Those occurring in clusters without easily recognizable form, Fig. 1c.

When damage patterns were examined together with the synoptic features with which they occurred, it was found that:

(a) Swath-type damage patterns lying northwest to southeast were associated with fast-moving $(20 \mathrm{mph}$ or more) cold fronts or squall lines strung across the State in a southwest to northeasterly direction, moving southeastward. Individual cloud masses in the frontal structure apparently received impetus to reach greater heights-and thus potential hailforming levels-than the rest, and these sections of the fronts gave continuous hail along their narrow width, finally dying out as the fronts became less active (Fig. 2a).

(b) Groups of claims along a straight line or gentle curve, often, but not always, lying southwest to northeast, appeared to be associated with slow moving cold or warm fronts with or without waves moving along them. The closer to stationary the front, the denser the concentration of hail claims. The presence of waves resulted in a wider band of hail damage than was the case where no waves were present (Fig. 2b).

(c) Groups of claims without recognizable form occurred round the apex of frontal systems associated with depressions moving usually from west to east across Nebraska or southern sections of South Dakota (Fig. $2 c$ ); and with wide open warm sectors filled with warm, moist, unstable Gulf air (Fig. 2d). Combinations of these synoptic forms, resulting in damage patterns that are occasionally difficult to interpret without resort to the synoptic map, are the rule rather than the exception. 


\section{GROUND HAIL DAMAGE PATTERNS}

\section{GROUP I}

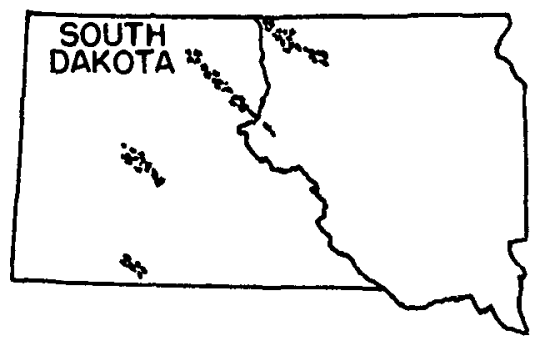

GROUP 2

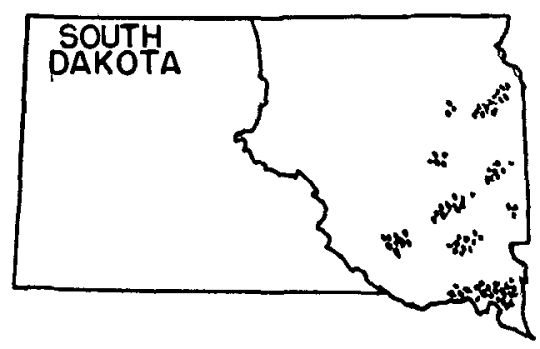

GROUP 3

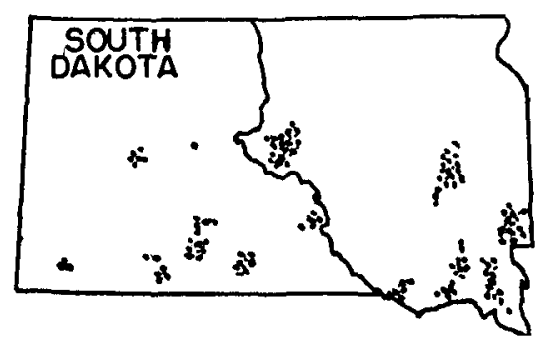

- hall claims

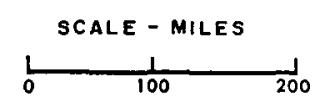

FIG. 1. Ground hail damage patterns: (a) Group 1. NW-SE swaths; (b) Group 2. SW-NE bands; (c) Group 3. Clustered hail.

An analysis of the frequency of occurrence of the major hailstorm patterns of South Dakota with their associated synoptic forms, for a series of crop seasons over which relatively complete data are available, is shown in Table 1.

\section{Forecasting hail damage}

Although it is an interesting exercise to be able to relate ground hail damage patterns to specific synoptic features, the latter recur many times without producing hail. The forecaster is still dependent initially therefore on radiosonde data, the familiar Showalter Stability Index, and radar information concerning cloud height and echo brightness (Douglas and Hitschfeld, 1959) for his first clues as to the probable presence or imminent formation of hail in a given cloud mass. Once this has been established, the geographical location of ground damage may be forecast as the result of studies of the kind outlined here.

A large measure of success in forecasting hail damage could only be expected, however, in the case of slow moving fronts or troughs where hail occurs in a relatively wide band parallel with the trough. Sporadic outbreaks of hail of the wide open, warm sector air-mass type, will continue to be difficult to place, as will the relatively narrow lines of damage formed at right angles to fast moving cold fronts. It has yet to be determined what factors are responsible for setting up the thermals that cause individual sections of the cloud mass comprising the air mass or front to rise to hail-forming heights, while others remain relatively inactive. It would seem, at first sight, that in some parts of South Dakota this "triggering effect" could be caused by topography. There is, for example, as much as 500 to $800 \mathrm{ft}$ difference in elevation from plain to hilltop along the Coteaux scarps, and from River to Bluff tops along the Missouri valley.

A detailed study of ten years of swath-type storm origins in relation to ground height, for the area of the State east of the Missouri River, is summarized diagrammatically in Fig. 4. Seventy-two per cent of the straight line hail storms of the period 1951 to 1960 appear to have originated over higher ground. But when numbers of hail storm origins over equal areas of hill and valley country are examined side by side, they are found to be about identical. Average numbers of hail claims per township over the period 1956 to 1960, plotted against the average elevation of the township, give an entirely random result. Thus, there is no clear statistical evidence for thinking that topography alone provides the incentive for the development of vigorous thermals, in this area at least,${ }^{1}$ and other parameters possessing theoretical relevance to the subject, are either not measured or are too complex to be capable of direct correlation with known results. Once the swaths have started however, and their direction is known, they can be expected to be $150-200 \mathrm{mi}$ long with widths varying from 5 to $15 \mathrm{mi}$.

\footnotetext{
${ }^{1}$ Frisby, E. M., 1961: Hailstorm distribution in the upper great plains of the United States. Raven Industries Technical Paper No, 26
} 
TABLE 1. An analysis of the frequency of occurrence of the major hail storm patterns of South Dakota with their associated synoptic forms.

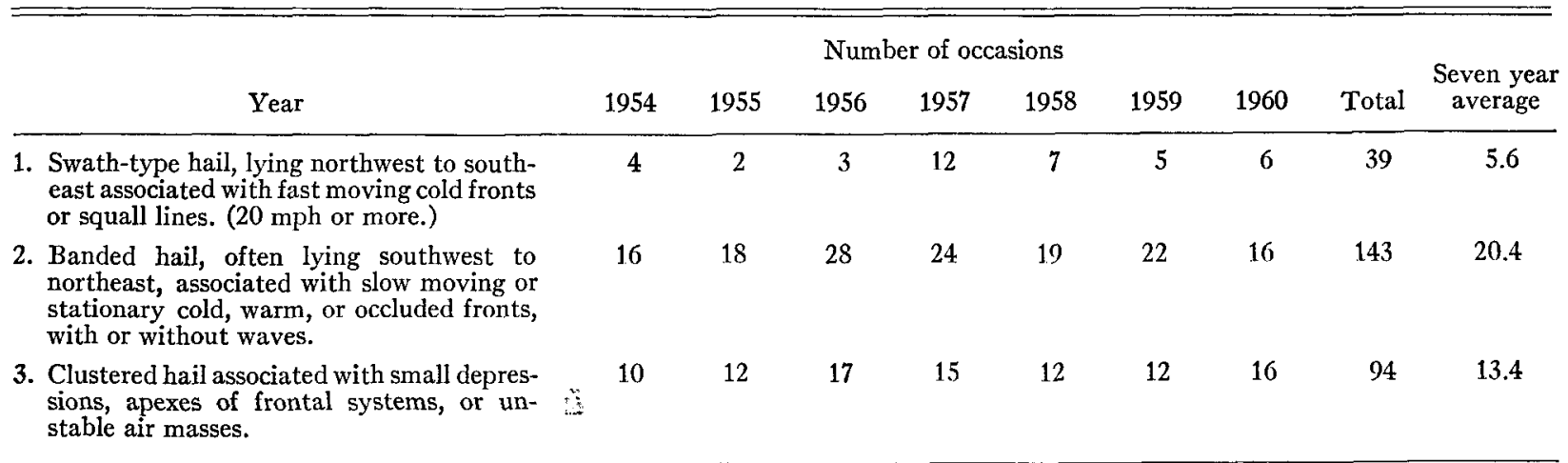

HAIL DAMAGE PATTERNS AND THE SYNOPTIC MAP

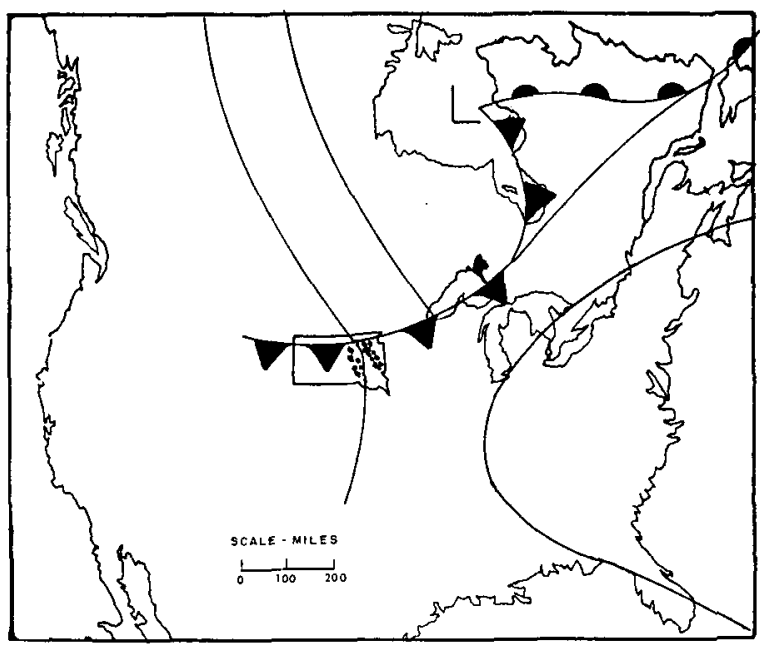

FAST MOVING COLD FRONT

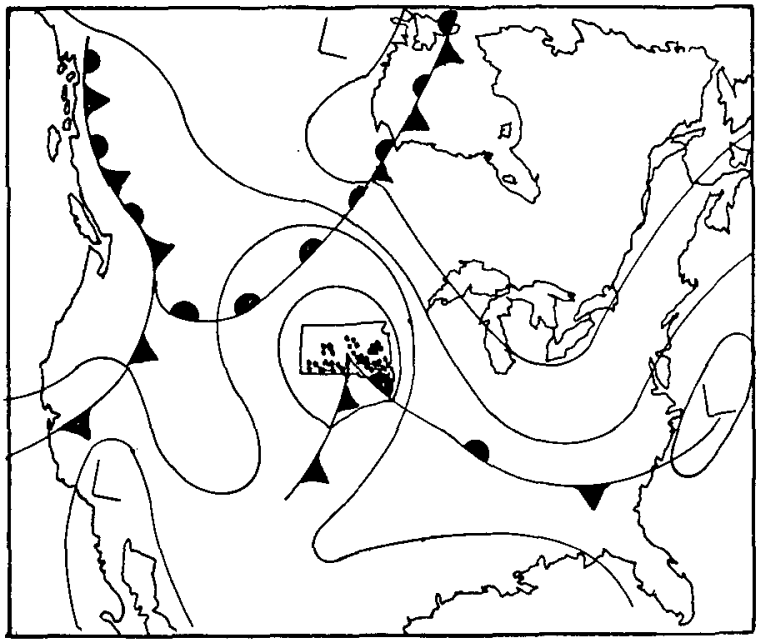

LOW PRESSURE SYSTEM

18 JUNE 1959

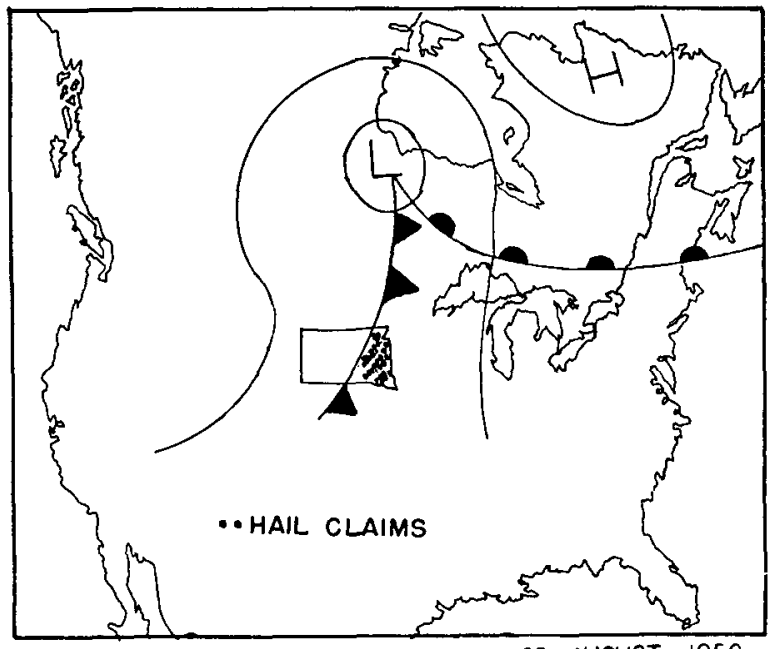

SLOW MOVING FRONTAL SYSTEM 23 AUUUST 1959

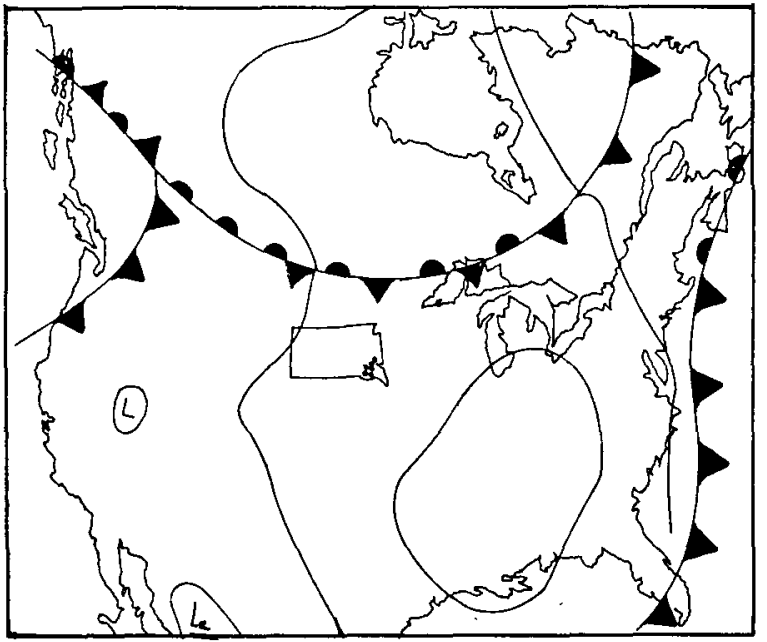

UNSTABLE AIR MASS

3 JUNE 1959

FIG. 2. Hail damage patterns and the synoptic maps: (a) Fast moving cold front (18 July 1959); (b) Slow moving frontal system (23 August 1959); (c) Low pressure system (18 June 1959); (d) Unstable air mass (3 June 1959). 
PRECIPITATION \& HAIL CLAIM PATTERN

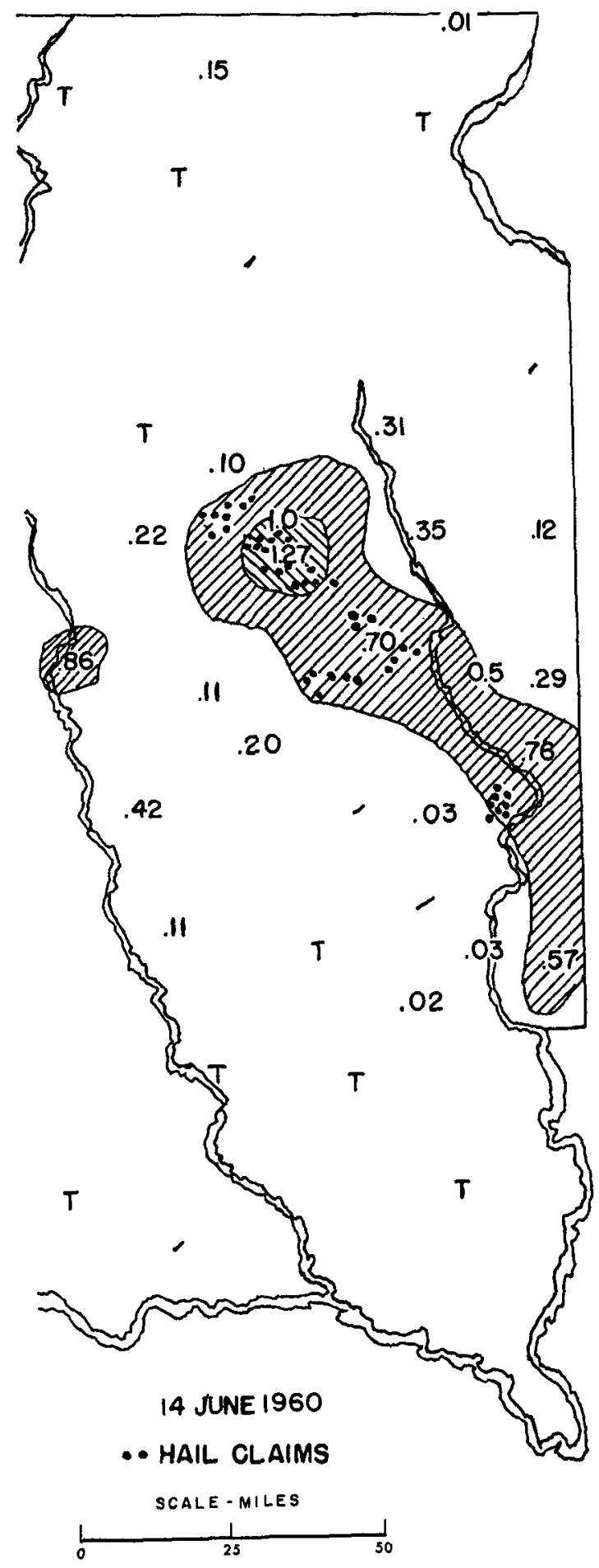

FIG. 3. Precipitation and hail claim pattern, 14 June 1960.

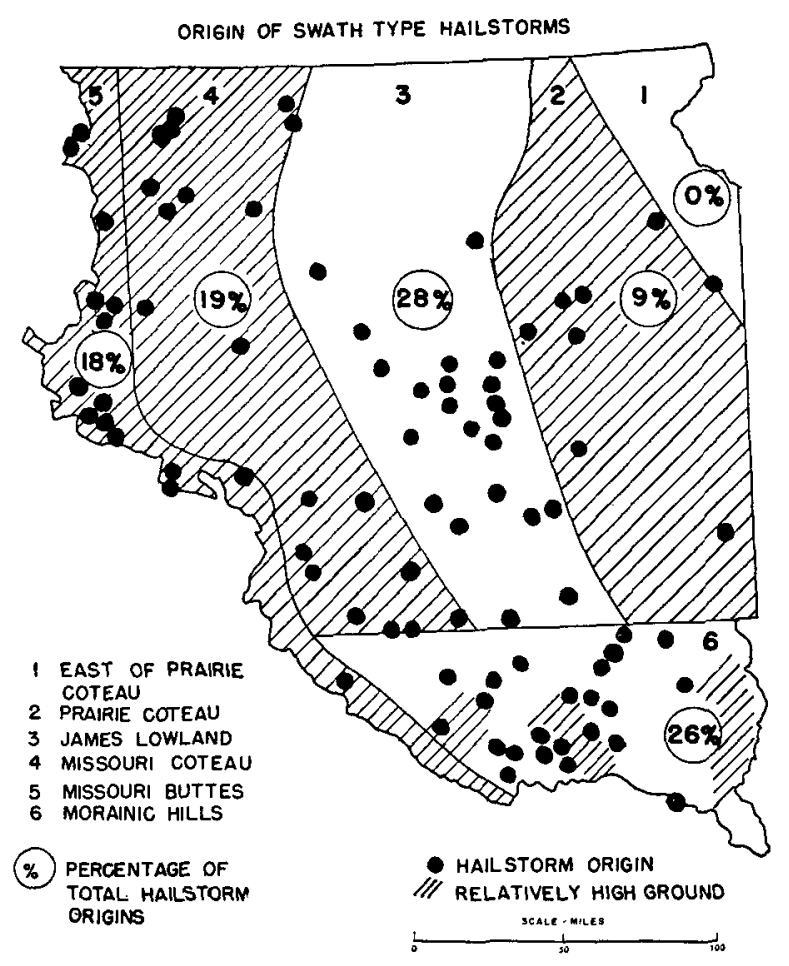

FIG. 4. Origin of swath type hailstorms, 1951-1960.

A similar conclusion concerning swath width was reached in Illinois. ${ }^{2}$

An interesting feature of hail damage associated with slow moving fronts or troughs is that the hail band parallel to the trough does not become a zone of continuous hail as the front advances, but takes the form of a series of parallel bands of damage with gaps of no damage between. Several theories have been put forward to explain this "jump" phenomenon, possibly the most plausible of which is, that the front does not experience constant speed of movement, but advances erratically, in a succession of stops and starts. Revitalization must continue to take place, as long as the qualities of both air masses comprising the front remain the same. Hail bands of this slow moving frontal type, also, are usually 5-15 mi wide, but may be twice this width in the case of stationary fronts or troughs, or when active waves are moving along the fronts.

An attempt was made to see what relationship hail damage bore to the overall precipitation pattern. Precipitation values were plotted for individual hailstorms occurring during 1959 and 1960. In case after case, a

2 Huff, F. A., 1960: Relations between summer hailstorms in Illinois and associated synoptic weather. Report prepared by Illinois State Water Survey for Crop Hail Actuarial Association, Chicago, Ill. 
damaging hail swath coincided with the highest precipitation values of the precipitation pattern and formed a hard core from which precipitation values decreased in all directions (Fig. 3).

\section{Conclusions}

Once the likelihood of hail fall has been established by radar and empirical means, a study of past years of hail claim data in association with the synoptic maps will in many cases provide the forecaster with an additional bit of guidance with regard to the geographical determination of those areas about to experience damaging hail.
Acknowledgments. This investigation is part of a research program on hailstorms in the northern Great Plains of the United States sponsored by the National Science Foundation under contract NSF C-196 with Raven Industries. The writer is indebted to the Crop Hail Actuarial Association of Chicago for permission to use its data and reports, and to the Sioux Falls Weather Bureau for surface synoptic details not given on the simplified form of the published daily weather maps.

\section{REFERENCE}

Douglas, R. H., and W. Hitschfeld, 1959: Patterns of hailstorms in Alberta. Quart. J. R. meteor. Soc., 85, 105-119. 